\title{
Catalysis by Cross-Linked Cationic Polymers. I. The Decarboxylation of 6-Nitrobenzisoxazole-3-carboxylate Anion Catalyzed by Cross-Linked Polystyrene Resins Having Quaternized Ammonium Chloride
}

\author{
Noboru YAMAZAKI, ${ }^{*}$ Seiichi NAKAHAMA, Akira HIRAO, \\ and Juheiji KAWABATA \\ Department of Polymer Science, Tokyo Institute of Technology, \\ Meguro-ku, Tokyo 152, Japan.
}

(Received September 14, 1979)

\begin{abstract}
Catalysis by cationic polyelectrolytes of the decarboxylation of 6nitrobenzisoxazole-3-carboxylate anion was studied in a buffer solution. The polyelectrolytes used were insoluble cross-linked styrene-divinylbenzene copolymers containing quaternized ammonium chloride and water-soluble polystyrene analogue. Tne cross-linked polymer catalysts showed much higher catalytic activities for decarboxylation than that of a linear polymer analogue, a cationic micelle, or a monomeric quaternary ammonium salt. The cross-linked polymers which acted as efficient catalysts caused hypsochromic shift of the fluorescence maximum wavelength of 6-ptoluidino-2-naphthalene sulfonate in the fluorescent emission spectra. From this observation, the acceleration by cross-linked polymer catalysts was apparently caused by the formation of a hydrophobic microenvironment around the catalytic sites. A reaction mechanism in the heterogeneous system was proposed on the basis of kinetic studies of decarboxylation.
\end{abstract}

KEY WORDS Polymer Catalyst / Decarboxylation / 6-Nitrobenzisoxazole3-carboxylate / Cross-Linked Cationic Polymer / Polystyrene Resin Having Quaternized Ammonium Chloride / Hydrophobic Microenvironment / Fluorescent Emission Spectrum / Rate Enhancement / Hetrogeneous System /

Recently, catalysis in micellar and macromolecular systems in aqueous solutions has received significant attention from a biological standpoint of view. Structural and kinetic analogies between micellar and macromolecular catalysts and enzymes have been discussed by many workers. ${ }^{1}$ It has been pointed out that the hydrophobic domains in these catalysts play important roles in accelerating reactions. In order to study such environmental effects of these catalysts, decarboxylations of carboxylic acids were investigated, since they are unimolecular, and not catalyzed by acids or bases and their reaction rates depend greatly on the solvents, ${ }^{2}$ micelles, ${ }^{3}$ and polymer catalysts ${ }^{4,5}$ added. In particular, the 6nitrobenzisoxazole-3-carboxylate anion, $\mathrm{S}$, has been employed as a substrate by many investigators since it enables the reaction to be followed easily.

It was found that the decarboxylation of S (eq 1) was accelerated markedly by cationic micelles, such

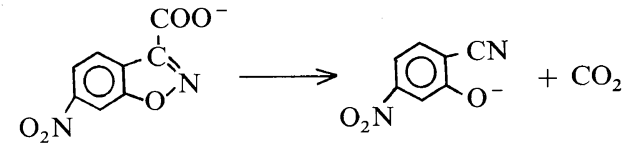

(P)

as cetyltrimethylammonium bromide, ${ }^{3}$ charged polysoaps derived from poly(4-vinylpyridine)s and poly(2-ethyl-1-vinylimidazole), ${ }^{4}$ and modified poly(ethylenimine)s containing apolar lauryl groups, ${ }^{5}$ although the monomeric electrolyte does not show the catalytic effect. These studies show the importance of the hydrophobic environment surrounding the catalytic sites in the activation of a substrate anion. The hydrophobic environment evidently stabilizes the charge delocalized transition state of the benzisoxazole carboxylate anion and thereby accelerates the rate of the decarboxylation. Berezine also emphasized the significance of the desolvation 
of the carboxylate anion in the hydrophobic environment of micelles, and claimed that the electrostatic interaction with the positive charge of the micelle was manifest only in binding the substrate anion to the micelles. ${ }^{6}$ A similar argument was presented on the decarboxylation of the tetramethylguanidine salt of 6-nitrobenzisoxazole-3-carboxylic acid in a variety of solvents. ${ }^{2}$

Cross-linked cationic polyelectrolytes have recently been developed as heterogeneous phase transfer catalysts in synthetic procedures by Regen ${ }^{7,8}$ and Colonna. ${ }^{9}$ These authors suggest that microenvironments of reactive sites along the cross-linked polymer backbone is predominantly non-aqueous, although this has not been clearly shown yet.

This paper describes the results of the decarboxylation of the 6-nitrobenzisoxazole-3-carboxylate anion, S, catalyzed by cross-linked cationic polyelectrolytes, I, polystyrene resins with different degrees of cross-linking and ring substitution by quaternary groups. A marked rate enhancement of the reaction with I has been found compared with homogeneous systems, II, and a reaction mechanism is proposed, based on kinetic study.

\section{EXPERIMENTAL}

\section{Materials}

6-Nitrobenzisoxazole-3-carboxylic acid According to the procedure reported by Borsche, ${ }^{10}$ methyl 6-nitrobenzisoxazole-3-carboxylate was prepared from methyl 2,4-dinitrophenylacetate, sodium methoxide, and isoamyl nitrite in methanol. A solution of the methyl ester in $80 \% \mathrm{H}_{2} \mathrm{SO}_{4}$ was heated at $70^{\circ} \mathrm{C}$ for $30 \mathrm{~min}$ and then poured onto ice to precipitate the acid. The hydrolysis was completed by repeating this treatment twice. The acid was recrystallized from methanol, mp $167-169^{\circ} \mathrm{C}$. [lit. ${ }^{10}$ $\mathrm{mp} 167-169^{\circ} \mathrm{C}$ (monohydrate)]; yield, $90 \%$.

Hexadecyltrimethylammonium bromide (CTABr) and Benzyltriethylammonium Chloride. The ammonium salts were purchased from Wako Pure Chemical Industries, and recrystallized from ethanol before use.

Cross-Linked Polystyrene Having Quaternary Ammonium Groups. Polystyrene resin beads were obtained by the suspension polymerization of styrene and divinylbenzene. The polymerization was

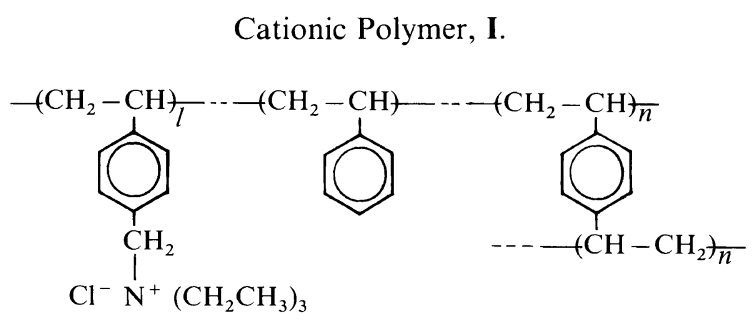

Cationic Polymer, II.

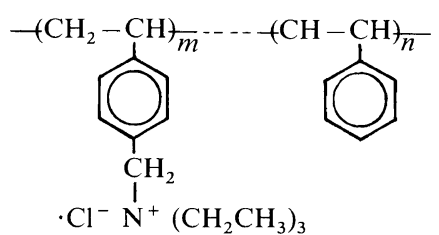

initiated with a radical initiator by using hexane or toluene as diluent and poly(vinyl alcohol) as a protective colloid at $70^{\circ} \mathrm{C}$ for $48 \mathrm{~h}$. The particle diameter of the polymer beads was controlled by the change in amount of poly(vinyl alcohol) and agitation speed. The resulting beads were collected and sieved, and the fractions were washed with water, acetone, and methanol, and dried in vacuo.
Microporous polystyrene beads S-X2 (200-400 mesh, $2 \%$ divinylbenzene) were purchased from BioRad Laboratories. Chloromethylated cross-linked polystyrene resins were obtained using established procedures. ${ }^{11} \mathrm{~A}$ mixture of $1.0 \mathrm{~g}$ of the chloromethylated polystyrene, $8.0 \mathrm{~g}$ of triethylamine and $40 \mathrm{ml}$ of $\mathrm{N}, \mathrm{N}$-dimethylformamide was heated at $75^{\circ} \mathrm{C}$ for $120 \mathrm{~h}$. After filtration, the resin beads were washed 
with benzene and methanol successively and dried in vacuo at $70^{\circ} \mathrm{C}$ for $24 \mathrm{~h}$. The percent ring substitution of the pendant ammonium group was estimated from elemental analysis and potentiometric titration. The water-soluble polystyrene having quaternary ammonium groups, II, was prepared in a similar manner except for the reprecipitation with diethyl ether.

\section{Kinetic Measurements}

In a typical experiment, decarboxylation of the substrate, $\mathrm{S}$, was initiated by adding a solution of $125 \mathrm{mg}(0.6 \mathrm{mmol})$ of $\mathrm{S}$ in $1.0 \mathrm{ml}$ of ethanol to $99 \mathrm{ml}$ of a buffer solution containing 0.12 meq of a cationic polyelectrolyte at $30^{\circ} \mathrm{C}$, with continuous agitation by a magnetic stirrer. The solution was bufferd at $\mathrm{pH}$ 9.0 with $0.025 \mathrm{M}$ borate $(\mu=0.035)$. The progress of the reaction was followed spectrophotometrically at $410 \mathrm{~nm}$ (2-cyano-5-nitrophenolate, $\left.\mathrm{P} ; \varepsilon=2.8 \times 10^{3}\right)$, using a Hitachi 124 Spectrophotometer. In the case of the heterogeneous system, aliquots of the reaction mixture were quickly filtered and measured at desired time intervals.

\section{Fluorescence Spectrometry}

The fluorescent emission spectra of 6-p-toluidino2-naphthalenesulfonate (2,6-TNS) in the presence of cross-linked cationic polymer beads were measured on a JASCO FP-550 spectrofluorometer at room temperature in a buffer solution adjusted to $\mathrm{pH} 9$. The fluorescence measurements were directly performed in an aqueous dispersion of the ground cross-linked polymer beads with $1 \times 10^{-5} \mathrm{M}$ of the probe, $5 \times 10^{-4} \mathrm{eq}^{-1}$ of a cationic polymer, and 320 $\mathrm{nm}$ of excitation wavelength. The details of the experiment in which the fluorescent probe technique was used on heterogeneous cross-linked gel systems will be given elsewhere. ${ }^{12}$

\section{RESULTS AND DISCUSSION}

When a solution of 6-nitrobenzisoxazole-3carboxylic acid, $\mathrm{S}$, in ethanol was added to a buffer solution containing the cross-linked polycationic catalyst, I, the catalyst immediately turned red, followed by coloration of the aqueous solution, indicating the formation of product, P. From this visual observation in the heterogeneous system, it is suggested that the substrate anion incorporated by ion-exchange is catalyzed on the cross-linked polymer catalyst to form the product, which dissolves in an aqueous solution through ion-exchange between the product and the substrate, as will be shown later (eq 3).

Table I summarizes several characteristics of cross-linked polymers, I-1-I-5, and a soluble polymer analogue, II, such as the content of divinylbenzene in the gel, the percentage of ring substitution by quaternary ammonium groups, e.g., the ionexchange capacity, and the average particle diameter.

The time-conversion curves for the reactions are shown in Figure 1, under the condition of an excess substrate over the catalyst, $[\mathrm{S}]_{0} /[\mathrm{C}]_{0}=5.0$. It was

Table I. Several characteristics of cross-linked polymers, I, and a water-soluble analgogue, II

\begin{tabular}{|c|c|c|c|c|c|}
\hline \multirow{2}{*}{ Polymer } & \multirow{2}{*}{$\begin{array}{c}\mathrm{DVB}^{\mathrm{a}} \\
\mathrm{o} / \mathrm{a}\end{array}$} & \multirow{2}{*}{$\frac{\mathrm{RSP}^{\mathrm{B}}}{\%}$} & \multirow{2}{*}{$\begin{array}{c}\text { Ion-exchange capacity } \\
{\text { meq } g^{-1}}^{-1}\end{array}$} & \multirow{2}{*}{ Diluent $^{c}$} & \multirow{2}{*}{$\begin{array}{c}\text { Particle diameter } \\
\mu \mathrm{m}\end{array}$} \\
\hline & & & & & \\
\hline I-1 & 15 & 54 & 2.49 & Hexane & $5-20$ \\
\hline I-2 & 15 & 78 & 3.12 & Toluene & $5-20$ \\
\hline I-3 & 8 & 92 & 3.55 & Hexane & $5-20$ \\
\hline $\mathbf{I}-4^{\mathrm{d}}$ & 2 & 22 & 1.60 & d & $30-70$ \\
\hline $\mathbf{I}-5^{\mathrm{d}}$ & 2 & 79 & 3.42 & $\mathrm{~d}$ & $30-70$ \\
\hline II & 0 & 70 & 2.92 & - & - \\
\hline
\end{tabular}

a Divinylbenzene content $\left(\mathrm{wt}^{\mathrm{o}} \mathrm{\%}\right)$ in the polystyrene gel.

b Percentage of ring substitution by ammonium groups.

c Cosolvent used as diluent of monomer during the suspension polymerization.

d Commercial available Bio-beads S-X2. The information of dilutent is not available. 


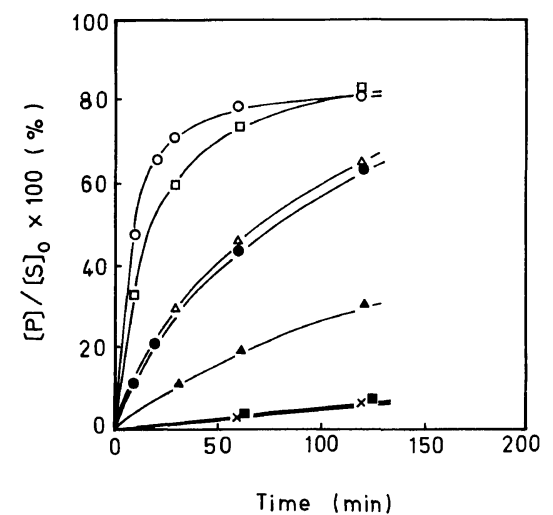

Figure 1. Rate of release of 5-nitro-2-cyanophenolate during decarboxylation of 6-nitrobenzisoxazole-3carboxylate anion catalyzed by various quaternary ammonium salts: $[\mathrm{S}]_{0}, 6 \times 10^{-3} \mathrm{M} ;[\mathrm{C}]_{0} /[\mathrm{S}]_{0}, 0.2$; temp, $30^{\circ} \mathrm{C}$; $\mathrm{pH}, 9.0$ with $0.025 \mathrm{M}$ borate $(\mu, 0.035) ; \bigcirc, \mathbf{I - 1} ; \square, \mathbf{I}-2 ; \triangle$, I-4; $, \mathbf{I I}, \mathbf{\Delta}, \mathrm{CTABr} ; \boldsymbol{\square}, \mathrm{BTACl} ; \times$, none.

found that polymer catalysts I and II significantly accelerated the decarboxylation of $\mathrm{S}$, while the monomeric analogue, benzyltriethylammonium chloride (BTACl), did not exhibit this effect. The initial reaction rates in the presence of these polymer catalysts exceeded by a factor of four to ten that of a typical micellar catalyst, hexadecyltrimethylammonium bromide (CTABr). In addition, it is of interest that the cross-linked polymer catalysts, I-1 and I-2, show much higher activities than the homogeneous one, II, in spite of their heterogeneous characters.*

\section{Kinetics of Decarboxylation of 6-Nitrobenzisoxazole- 3-Carboxylate Anion, $S$}

The decarboxylation of $\mathrm{S}$ catalyzed by cationic polysoaps $^{4}$ and quaternized poly(ethylenimines) ${ }^{5}$ has been known to follow the general mechanism established by Michaelis and Menten ${ }^{13}$ as shown in eq 2, where $\mathrm{C}$ and $\mathrm{S}$ represent the cationic site on the

* The non cross-linked linear catalyst became insoluble in water in the case of the percentage of ring substitution by ammonium group less than $30 \%$, and manifested lower activity than that of a water-soluble one, II. The crosslinked structure of the polyer catalyst, whatever the reason, would play an important role in the rate enhancement of the decarboxylation reaction. polymer and the carboxylate substrate, respectively.

$$
\mathrm{S}+\mathrm{C} \underset{k_{-1}}{\stackrel{k_{1}}{\rightleftarrows}} \mathrm{SC} \stackrel{k_{\mathrm{d}}}{\longrightarrow} \text { Product }+\mathrm{C}
$$

In catalytic reactions of this study, the saturation behavior of the rate constant was also observed under the condition of an excess of the water-soluble catalyst, II, in the homogeneous system (Figure 2), similar to that reported by Kunitake ${ }^{4}$ and Klotz. ${ }^{5}$

In the heterogeneous system, under the condition of an excess of catalyst over the substrate, e.g., $[\mathrm{C}]_{0} \gg[\mathrm{S}]_{0}$, the rates at which the substrate decreased and the product produced could not be measured since the substrate and the product were adsorbed completely on the heterogeneous catalyst and did not appear in the solution. Thus, the kinetic study of the reaction catalyzed by $\mathbf{I}$ was performed under the condition of an excess of substrate over the catalyst, e.g., $[\mathrm{C}]_{0} \ll[\mathrm{S}]_{0}$.

Under the conditions above, time-conversion curves of the decarboxylation catalyzed by $\mathbf{I}-\mathbf{1}$ are illustrated in Figure 3. The apparent conversions were reached at $80 \%$ and $95 \%$ when the ratios of $[\mathrm{C}]_{0}$ to $[S]_{0}$ were $20 / 100$ and $5 / 100$, respectively, even after completion of the reaction. This indicates that the amount of product equivalent to the catalyst concentration still remained at the catalytic site, probably as a catalyst-product complex. The formation of the complex, followed by accumulation of the product that caused a rate decrease by product inhibition,,${ }^{14}$ is also supported by the fact that the

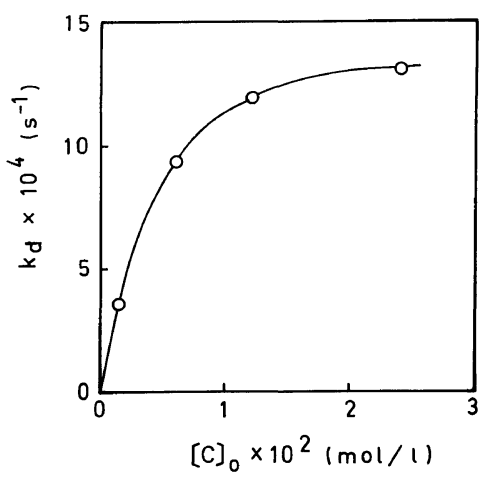

Figure 2. Rate constants for decarboxylation of the 6nitrobenzisoxazole-3-carboxylate anion catalyzed by II as a function of catalyst concentration; $[\mathrm{S}]_{0}, 1.2 \times 10^{-3} \mathrm{M}$; $\mathrm{pH}, 9.0$; temp, $30^{\circ} \mathrm{C}$. 
Catalysis by Cross-Linked Cationic Polymers. I.

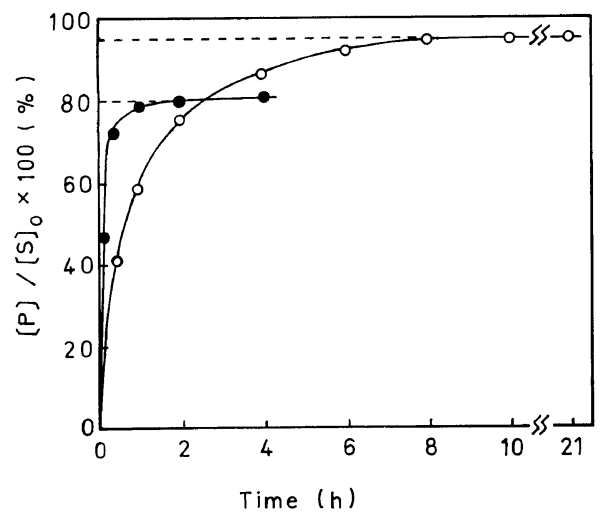

Figure 3. Time-conversion curves on the decarboxylation of S catalyzed by cross-linked polymer catalysts, I1: $[\mathrm{S}]_{0}, 6 \times 10^{-3} \mathrm{M} ; \mathrm{pH}, 9.0$; temp, $30^{\circ} \mathrm{C} ; \mathrm{O},[\mathrm{C}]_{0} /[\mathrm{S}]_{0}$, $5 / 100 ; \bigcirc,[\mathrm{C}]_{0} /[\mathrm{S}]_{0}, 20 / 100$.

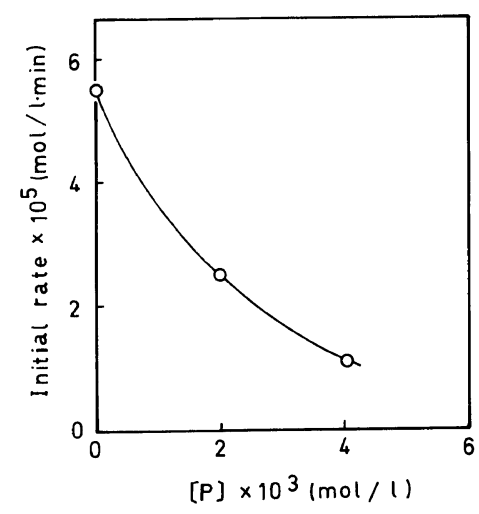

Figure 4. Initial rate of release of product, $P$, in the decarboxylation of $\mathrm{S}$ catalyzed by $\mathbf{I}-\mathbf{1}$ plotted against the concentration of $\mathrm{P}$ : $[\mathrm{S}]_{0}, 2 \times 10^{-3} \mathrm{M}$; $[\mathrm{C}]_{0}, 3 \times 10^{-4} \mathrm{M}$.

rate was observed to decrease as the product concentration increased, as shown in Figure 4.

Considering the product inhibition by the complex, and the observations mentioned before in RESULTS AND DISCUSSION, we have derived the following scheme for the heterogeneous system.

$\mathrm{S}+\mathrm{C} \underset{k_{-1}}{\stackrel{k_{1}}{\rightleftarrows}} \mathrm{SC} \stackrel{k_{2}}{\longrightarrow} \mathrm{PC} \frac{+\mathrm{S}, k_{3}}{k_{-3}} \mathrm{SC}+\mathrm{P}$

This formulation treats the first step of the formation of the SC complex as an equilibrium and the second step in which the conversion of $\mathrm{S}$ into $\mathrm{P}$ on the catalytic site occurred as irreversible. The final step is the release of $P$ from the catalyst through the ionexchange between $\mathrm{P}$ and $\mathrm{S}$. From the reaction scheme shown in eq 2 and 3 , it may be suggested that the first-order rate constant, $k_{2}$, in the heterogeneous system is comparable to $k_{\mathrm{d}}$ in the homogeneous system, provided the SC complex formed for an instant of time before breaking down into the product in the heterogeneous system.

The rate of the SC complex produced in the first step of eq 3 can be measured spectrophotometrically by the decrease in the absorbance of $\mathrm{S}$ in an aqueous solution separated from the heterogeneous catalyst by filtration. Since absorbance for $S$ $\left(\varepsilon_{275}=1.13 \times 10^{4}\right)$ and the product, $\mathrm{P}\left(\varepsilon_{275}=9.5 \times 10^{3}\right.$ and $\varepsilon_{410}=2.8 \times 10^{3}$ ) overlapped each other in the ultraviolet region, the amount of decrease in $\mathrm{S}$ was estimated by eq 4 , where $V(1), \Delta A_{275}$, and $\Delta A_{410}$ are the volume of the filtrate aqueous solution, and increments of absorbances at 275 and $410 \mathrm{~nm}$, respectively.

$$
\begin{aligned}
\mathrm{S}(\mathrm{mol}) \text { decreased } & =-V \frac{\Delta A_{275}}{\varepsilon^{\mathrm{S}}}+\frac{\varepsilon_{275}^{\mathrm{S}}}{\varepsilon_{275}^{\mathrm{S}}{ }^{-} \varepsilon^{\mathrm{P}}{ }_{275} \varepsilon^{\mathrm{P}}{ }_{410}} \Delta A_{410} \\
& =-10^{-5} V\left(8.9 \Delta A_{275}+5.7 \Delta A_{410}\right)
\end{aligned}
$$

This decrease in the amount of S corresponded to that of the $\mathrm{S}$ adsorbed on the catalyst as a SC complex. This equation applies only to the heterogeneous system, since in the systems using soluble catalysts like micelles, $\mathrm{S}$ is not separable from the SC complex in solution.

The amount of adsorbed $\mathrm{S}$ thus obtained and the amount of $\mathrm{P}$ produced and released from $\mathrm{C}$ against time are plotted in Figure 5. The quantity of the adsorbed $\mathrm{S}$ levelled off within a minute and the value of the plateau approximately corresponded to the amount of $\mathrm{N}^{+}$group in $\mathbf{I - 5}$, while the decarboxylation reaction was far from complete even after three hours. This demonstrates that the rate of the SC complex formation proceeds much faster than the rate at which $\mathrm{P}$ is produced and released from $\mathrm{C}$. The same phenomenon has been experimentally confirmed for all the reactions in the presence of cross-linked catalysts, I-1-I-5 examined here. Accordingly, in the heterogeneous system of this study, the diffusion of S during the course of the SC complex formation might not be a rate-determining step of the decarboxylation reaction, since the ionexchange between $\mathrm{S}$ and $\mathrm{C}$ is considered to be very 


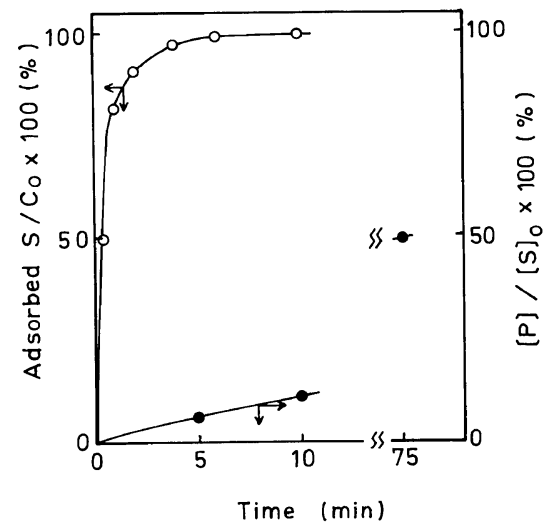

Figure 5. The rates at which $\mathrm{S}$ is adsorbed and $\mathrm{P}$ is produced and released as a function of time: $[\mathrm{S}]_{0}$, $6 \times 10^{-3} \mathrm{M} ;[\mathrm{C}]_{0}, 1.2 \times 10^{-3} \mathrm{M}$; catalyst, I-5; pH, 9.0; temp, $30^{\circ} \mathrm{C}$; $\mathrm{O}, \mathrm{S}$ adsorbed; $\mathrm{O}$, $\mathrm{P}$ produced and released.

rapid. But this does not seem likely, at least as a general phenomenon in heterogeneous systems.

From the final step in eq 3, the apparent rate of $\mathbf{P}$ produced can be expressed.

$$
V=\frac{\mathrm{d}[\mathrm{P}]}{\mathrm{d} t}=k_{3}[\mathrm{PC}][\mathrm{S}]-k_{-3}[\mathrm{SC}][\mathrm{P}]
$$

If it is assumed that the steady-state rate equation is achieved in which the concentration of the intermediate is constant, ${ }^{14}$ i.e., $\mathrm{d}[\mathrm{PC}] / \mathrm{d} t=0$

$\frac{\mathrm{d}[\mathrm{PC}]}{\mathrm{d} t}=k_{2}[\mathrm{SC}]+k_{-3}[\mathrm{SC}][\mathrm{P}]-k_{3}[\mathrm{PC}][\mathrm{S}]=0$

As described above, when the SC complex formation is sufficiently rapid and $\mathrm{P}$ is quantitatively adsorbed onto the catalytic sites, the PC complex is formed, and all catalytic sites may be considered to be occupied by $\mathrm{S}$ and $\mathrm{P}$.

Thus,

$$
[\mathrm{C}]_{0}=[\mathrm{SC}]+[\mathrm{PC}]
$$

The material balance is now expressed by

$$
[\mathrm{S}]_{0}=[\mathrm{S}]+[\mathrm{P}]+[\mathrm{C}]_{0}
$$

Using the four equations (5), (6), (7), and (8), the apparent rate of the production of $P$ can be expressed in eq 9.

$$
V=\frac{\mathrm{d}[\mathrm{P}]}{\mathrm{d} t}=\frac{k_{2} k_{3}[\mathrm{C}]_{0}[\mathrm{~S}]}{k_{2}+k_{3}[\mathrm{~S}]+k_{-3}[\mathrm{P}]}
$$

Equation 9 may then be rearranged to give eq 10 as a linear transform.

$$
\frac{[\mathrm{C}]_{0}}{V}=\frac{1}{k_{2}}+\frac{1}{k_{3}[\mathrm{~S}]}+\frac{k_{-3}[\mathrm{P}]}{k_{2} k_{3}[\mathrm{~S}]}
$$

When plotted $[\mathrm{C}]_{0} / V$ against

$$
[\mathrm{P}] /[\mathrm{S}]\left[\equiv[\mathrm{P}] /\left([\mathrm{S}]_{0}-[\mathrm{C}]_{0}-[\mathrm{P}]\right)\right],
$$

it should be noticed that a linear plot is obtained until below $40 \%$ conversion. At the $40 \%$ conversion, deviation occurrs as anticipated, but by adding the substrate to the system the plot gives a straight line again as shown in Figure 6. The second term of eq 10 , therefore, may be neglected at the initial stage, before there is a $40 \%$ conversion. Finally, we find a slightly modified form of eq 10 , as follows.

$$
\begin{aligned}
\frac{V}{[\mathrm{C}]_{0}} & =k_{2}-\frac{k_{-3}}{k_{3}} \frac{V}{[\mathrm{C}]_{0}} \frac{[\mathrm{P}]}{[\mathrm{S}]} \\
& =k_{2}-\frac{k_{-3}}{k_{3}} \frac{V}{[\mathrm{C}]_{0}} \frac{[\mathrm{P}]}{[\mathrm{S}]_{0}-[\mathrm{C}]_{0}-[\mathrm{P}]}
\end{aligned}
$$

A plot of $V /[C]_{0}$ against

$$
V /[\mathrm{C}]_{0}\left\{[\mathrm{P}] /\left([\mathrm{S}]_{0}-[\mathrm{C}]_{0}-[\mathrm{P}]\right)\right\},
$$

illustrated in Figure 7, provides a good straight line within experimental error, and whose intercept yields the value of $k_{2}$.

The value of $k_{2}$ for various cross-linked polymer catalysts, $\mathbf{I}-\mathbf{1}-\mathbf{I}-\mathbf{5}$, thus obtained and those of $k_{\mathrm{d}}$ for

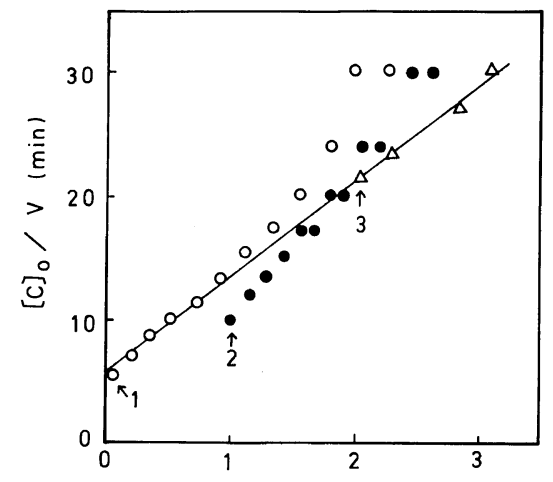

$[\mathrm{P}] /[\mathrm{S}]_{0}-[\mathrm{C}]_{0}-[\mathrm{P}]$

Figure 6. Variation of $\left[\mathrm{C}_{0} / V\right.$ as a function of

$$
[\mathrm{P}] /\left([\mathrm{S}]_{0}-[\mathrm{C}]_{0}-[\mathrm{P}]\right)
$$

for the runs in Figure 4: $[\mathrm{S}]_{0}, 2 \times 10^{-3} \mathrm{M} ;[\mathrm{C}]_{0}, 3 \times 10^{-4} \mathrm{M}$; $1(\mathrm{O}),[\mathrm{P}]_{0}, 0 ; 2(\bullet),[\mathrm{P}]_{0}, 2 \times 10^{-3} \mathrm{M}$, and $3(\triangle),[\mathrm{P}]_{0}$, $4 \times 10^{-3} \mathrm{M}$. 


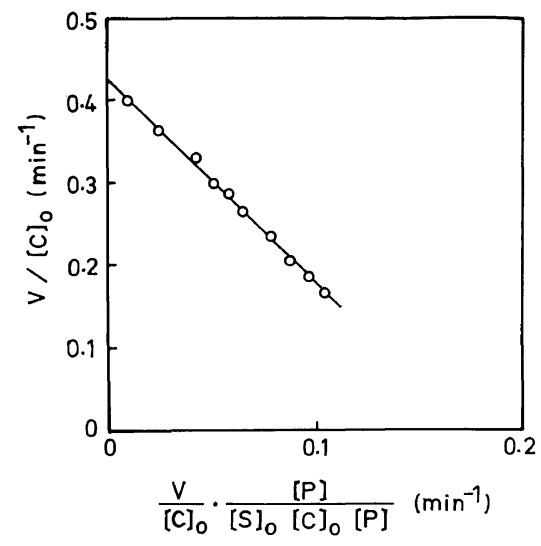

Figure 7. Variation of $V /[\mathrm{C}]_{0}$ as a function of

$$
V[\mathrm{P}] /[\mathrm{C}]_{0}\left([\mathrm{~S}]_{0}-[\mathrm{C}]_{0}-[\mathrm{P}]\right):
$$

catalyst, I-3; $[\mathrm{S}]_{0}, 6 \times 10^{-3} \mathrm{M} ;[\mathrm{C}]_{0}, 3 \times 10^{-4} \mathrm{M}$.

homogeneous catalysts are summarized in Table II. All the cross-linked polycations showed marked catalytic effects on the decarboxylation in an aqueous solution. The value of $k_{2}$ for I-1 was 1400 times greater than that of $k_{\mathrm{d}}$ in the absence of catalyst (No. 4 in Table II). It is evident that the cross-linked polycations are more effective catalysts than the non cross-linked soluble ones and a cationic micelle such as $\mathrm{CTABr}$ (No. 2 and 3).

Among the cross-linked catalysts, their structures may indeed influence the catalytic efficiency, result-

Table II. Rate constants for decarboxylation of the 6-nitrobenzisoxazole-3-carboxylate anion catalyzed by soluble and cross-linked polymer catalysts, $\mathbf{I}^{\mathbf{a}}$

\begin{tabular}{llll}
\hline & & \multicolumn{2}{c}{ Rate constant $\times 10^{3}$} \\
\cline { 3 - 3 } No. & Catalyst & \multicolumn{2}{c}{$\mathrm{s}^{-1}$} \\
\hline & & 0.006 & \\
\hline 1 & None & 0.3 & $k_{\mathrm{d}}{ }^{\mathrm{b}}$ \\
2 & CTABr & 1.3 & \\
3 & II & & \\
& & & \\
4 & $\mathbf{I}-1$ & $5.4 \pm 0.5$ & \\
5 & $\mathbf{I}-2$ & $7.2 \pm 0.2$ & $k_{2}{ }^{\mathrm{c}}$ \\
6 & $\mathbf{I}-3$ & $1.7 \pm 0.1$ & \\
7 & $\mathbf{I}-4$ & $1.4 \pm 0.3$ & \\
8 & $\mathbf{I}-5$ & & \\
\hline
\end{tabular}

a $\mathrm{Temp}, 30^{\circ} \mathrm{C} ; \mathrm{pH}, 9.0$.

b $[\mathrm{S}]_{0}, 1.2 \times 10^{-3} \mathrm{M} ;[\mathrm{C}]_{0}, 2.4 \times 10^{-2}$ eq $1^{-1}$.

c $[\mathrm{S}]_{0}, 6 \times 10^{-3} \mathrm{M} ;[\mathrm{C}]_{0}, 3 \times 10^{-4} \mathrm{eq} \mathrm{I}^{-1}$. ing in a variety of rate constants. For example, the catalyst, I-1, prepared from styrene divinylbenzene matrix using hexane as the diluent during the suspension polymerization, differed significantly in its efficiency from the catalyst, I-2, obtained from the same matrix but by using toluene as the diluent (No. 4 and 5). The catalysts, I-4 and I-5, prepared from commercially available cross-linked polystyrene (Bio-beads, S-X2, 2\% divinylbenzene; particle size, $30-70 \mu \mathrm{m})$ were generally not very effective, although they were lightly cross-linked. On the other hand, the percentage of ring substitution by ammonium cation on I series seemed not to affect the catalytic efficiency in the decarboxylation of $\mathrm{S}$ under aqueous conditions (No. 7 and 8).

\section{Fluorescence Spectrà of 6-p-Toluidino-2-naphthalene-} sulfonate in the Presence of the Polymer Catalysts

As mentioned in the introduction, many workers have pointed out the importance of a hydrophobic environment around the catalytic sites in the decarboxylation of $\mathrm{S}$. The use of substituted aminonaphthalene sulfonates as fluorescence hydrophobic probe in proteins and other macromolecules is well known. ${ }^{15}$ These compounds show characteristic changes in the location of their fluorescence maxima wavelength and fluorescence intensity, thus making them usable for determining hydrophobic regions in macromolecules. For example, Kunitake ${ }^{4}$ described the correlation between the hypsochromic shift of 1anilino-8-naphthalenesulfonate and reaction rate in the presence of partically laurylated poly(4-vinylpyridine).

In order to elucidate the correlation between the hydrophobicity around the catalytic sites and the activity of catalyst, we have investigated the hypsochromic shifts of 6-p-toluidino-2-naphthalenesulfonate $(2,6-\mathrm{TNS})$ as a hydrophobic probe for cross-linked and homogeneous catalysts in aqueous systems. Even in a heterogeneous system, we were able to measure the fluorescent emission spectra of 2,6-TNS in the presence of stable colloidal dispersions of the cross-linked polymer beads in water. In some cases, the grinding of the cross-linked polymer beads (average diameter $<1 \mu \mathrm{m}$ ) made possible a clearer fluorescent spectra without any change in the maximum wavelength, as compared with the case of non-grinding. To our knowledge, no fluorescent spectroscopic measurement has been reported in connection with the study of the microenvironment 
around the catalytic sites of cross-linked polymers. The fluorescence maximum of 2,6-TNS in water was at $500 \mathrm{~nm}$. This maximum significantly shifted to $456 \mathrm{~nm}$ in the presence of a soluble cationic polymer, II; however, the shift was only $10 \mathrm{~nm}$ in the presence of benzyltriethylammonium chloride, the monomeric analogue. This result implies that the polymer chain provides a more hydrophobic environment than the monomeric analogue. The most interesting feature in this study is that the cross-linked polymer catalyst, I-1, is more effective in causing a hypsochromic shift than is the soluble catalyst, II. Thus, the shifts to $440 \mathrm{~nm}$ and $443 \mathrm{~nm}$ were observed in the presence of $\mathbf{I}-\mathbf{1}$ and $\mathbf{I}-\mathbf{3}$, respectively, indicating that the hydrophobicity is further strengthened by cross-linking of the polymer chain. Consequently, it should be pointed out that the acceleration of the reaction by polymer catalysts can be interpreted as a reflection of the contribution of the more hydrophobic environment by the polymer chain and especially by the cross-linking of the polymer chain.

In the previous studies it was pointed out that the aggregation of positive charges on the micelles ${ }^{16}$ or polycationic crown ethers ${ }^{17}$ also contribute to the stabilization of the anionic transition state, thus causing the rate enhancement. For the cross-linked catalysts, I-4 and I-5, however, two resin catalysts possessing 79 and $22 \%$ ring substitution accelerated the reaction to the same magnitude (No. 7 and 8 in Table II). Accordingly, the effect of the aggregation of the ammonium cations seems to be less important.

In conclusion, the cross-linked polystyrene resins having quaternized ammonium groups are found to serve as efficient catalysts for the decarboxylation of 6-nitrobenzisoxazole-3-carboxylate anion in comparison with a soluble polymer analogue, a conventional cationic micelle, and a monomeric quaternary ammonium salts. The rate acceleration by cross-linked polymer catalysts seems due to the formation of a hydrophobic microenvironment on the catalytic sites in consistence with the correlation between spectra and kinetic data. In addition, we found that structural factors such as the degree of cross-linking and the particle size of the cross-linked polymer beads affected the catalytic efficiency. A detailed study of correlation between the structure of the cross-linked polymer catalyst and its catalytic activity is now in progress.

Acknowledgment. The authers are indebted to Professor Itaru Mita and Dr. Kazuyuki Horie for their technical assistance in measuring the fluorescent emission spectra, and for their helpful comments.

\section{REFERENCES}

1. J. H. Fendler and E. J. Fendler, "Catalysis in Micellar and Macromolecular Systems," Academic Press, New York, N.Y., 1975.

2. D. S. Kemp and K. G. Paul, J. Am. Chem. Soc., 97, 7305 (1975).

3. C. A. Bunton and M. J. Minch, Tetrahedron Lett., 3881 (1970).

4. T. Kunitake, S. Shinkai, and S. Hirotsu, J. Org. Chem., 42, 306 (1977).

5. J. Suh, I. S. Scarpa, and M. Klotz, J. Am. Chem. Soc., 98, 7060 (1976).

6. I. V. Berezin, K. Martinek, and A. K. Yatsimirski, Russ. Chem. Rev. (Engl. transl.), 42, 787 (1973).

7. S. L. Regen, J. Org. Chem., 42, 875 (1977).

8. S. L. Regen, J. Am. Chem. Soc., 97, 5956 (1975); ibid., 98, 6270 (1976).

9. S. Colonna, M. Cinouini, H. Molinari, H. Montanari, and P. Tundo, J. Chem. Soc., Chem. Comm., 394 (1976).

10. W. Borsche, Ber., 42, 1310 (1909).

11. K. W. Pepper, H. M. Paisley, and M. A. Young, $J$. Chem. Soc., 4097 (1953).

12. K. Horie, I. Mita, J. Kawabata, S. Nakahama, A. Hirao, and N. Yamazaki, Polym. J., 12, in press (1980).

13. L. Michaelis and M. L. Menten, Biochem. Z., 49, 333 (1913).

14. A. Cornish-Bowden, "Principles of Enzyme Kinetics," Butterworth \& Co., London, 1976, Chapter 2.

15. W. O. McClure and G. M. Edelmann, Biochemistry, 5, 1908 (1966); D. C. Turner and L. Brand, ibid., 7, 3381 (1968).

16. C. A. Bunton, M. J. Minch, J. Hidalgo, and L. Sepulveda, J. Am. Chem. Soc., 95, 3262 (1973).

17. S. C. Shar and J. Smid, J. Am. Chem. Soc., 100, 1426 (1978). 